\title{
Supporting information for "A general indication of the contemporary background levels of PCDDs, PCDFs, and coplanar PCBs in the ambient air over rural and remote areas of the United States."
}

Authors: David Cleverly*, Joseph Ferrario, Christian Byrne, Karen Riggs, Darrell Joseph, and Pamela Hartford.

* Office of Research and Development, National Center for Environmental Assessment (8623N), United States Environmental Protection Agency, Washington, DC, USA 20460.

*Email: cleverly.david@epa.gov

Number of pages: 15

Number of tables: 2

Number of figures: 5

Note: All references are consistent with the main text.

Analysis of NDAMN Samples. The harvested NDAMN samples were packaged with freezer packs and shipped overnight to an EPA laboratory for analysis. All samples were verified to have arrived cold, inspected, logged in, and stored in a freezer until analyzed. Samples were processed in analytical sets consisting of a group of 12: nine samples, one fortified laboratory control sample, and two method blanks. The QFFs from each individual field sample or field blank were combined with its corresponding PUF in a Soxhlet apparatus, fortified with the $17-{ }^{13} \mathrm{C}$ labeled 2,3,7,8-Cl substituted dioxins/furans and $7-{ }^{13} \mathrm{C}$ labeled coplanar PCBs (all twelve WHO coplanar PCB are analyzed after 2002) and extracted for 24 hours with toluene. The volume was reduced to $50 \mathrm{ml}$ and the solvent exchanged to hexane. The extracts were then stirred for 3 hours with 50 grams of acidified silica and passed through acidified and basic silica gel. The volume was then reduced to less then $1 \mathrm{ml}$ in a Zymark Turbovap II ${ }^{\mathrm{TM}}$ and fractionated on PX-21 
graphitized carbon. The dioxin fraction was then further "cleaned-up” on neutral alumina prior to analyses. All reagents were prepared according to procedures detailed in EPA Method 1613 and the analyses and QA/QC procedures and thresholds are consistent with those described in the method with several notable exceptions:

(1) Standard calibration solutions were prepared at lower concentrations. For the NDAMN, the lowest calibration standard contained $50 \mathrm{fg}$ of TCDD and $5 \mathrm{pg} / \mu \mathrm{l}$ of ${ }^{13} \mathrm{C}$ labeled surrogates; Method 1613's lowest calibration standard contains 500 fg and 100 $\mathrm{pg} / \mu \mathrm{l}$ of surrogates. The samples in this study are fortified to deliver $5 \mathrm{pg} / \mu \mathrm{l}$ where 1613 delivers $100 \mathrm{pg} / \mu \mathrm{l}$ from the same $20 \mu \mathrm{l}$ final volume. The lower ${ }^{13} \mathrm{C}$ surrogate fortification level allows for a more realistic approximation of the actual recovery of native analytes at the sub parts-per-trillion level and better approximates the behavior of trace levels of natives during sample processing and analyses;

(2) A DB-5MS column was used in place of the DB-5 specified by Method 1613 . The DB-5MS has superior separation of the 2,3,7,8-TCDD from the other tetra isomers and better resolves the 2,3,7,8-Cl -substituted dioxins and furans;

(3) Method 1613 uses an AX21/Celite mixture of graphitized carbon where we use a mixture consisting of $0.5 \mathrm{~g}$ of BioSil A silica gel and $0.5 \mathrm{~g}$ of Amoco PX-21 carbon. The eluting solvents and fractionization are also different. The column was conditioned with $10 \mathrm{ml}$ of 50/50 benzene/methylene chloride, $10 \mathrm{ml}$ toluene, and $5 \mathrm{ml}$ hexane. The sample was added to the column in $0.5 \mathrm{ml}$ hexane and following $2-0.5 \mathrm{ml}$ rinses of the sample. Fraction 1, containing most of the ortho-PCBs, was eluted with $4.5 \mathrm{ml}$ of $25 / 75 \mathrm{MeCl}$ /hexane. Fraction 2, collected in one vessel, consisted of $5.5 \mathrm{ml}$ of $\mathrm{MeCl}$ and contained the mono-ortho PCBs and $11.5 \mathrm{ml}$ of benzene/MeCl which contained the non-ortho 
PCBs. The column was then reversed and the dioxins and furans collected with $13 \mathrm{ml}$ of toluene. Fractions were reduced to less than $10 \mu \mathrm{l}$ and solvent exchanged with hexane and stored in the freezer until analyzed.

Instrumental Analyses. All analyses were performed on either a Kratos Concept or a Micromass Ultraspec high resolution mass spectrometer using isotope dilution. The HRMS was operated in the electron impact ionization mode using selected ion monitoring. Chromatographic separations were achieved using a Hewlett Packard 6890 Series II high-resolution gas chromatograph, utilizing a $60 \mathrm{~m}$ x $0.32 \mathrm{~mm}(0.25 \mu \mathrm{m}$ film thickness) DB-5MS capillary column. The GC conditions were optimized to completely separate the various 2,3,7,8-Cl-substituted dioxins/furans: initial oven temperature, $130^{\circ}$ $\mathrm{C}$; injector temperature, $270^{\circ} \mathrm{C}$; interface temperature, $275^{\circ} \mathrm{C}$; temperature programming, time $1,1.0 \mathrm{~min}$, rate $1,5^{\circ} \mathrm{C} / \mathrm{min}$, time $2,15.0 \mathrm{~min}$, rate $2,6^{\circ} \mathrm{C} / \mathrm{min}$; temperature $3,295^{\circ}$ C; injector, splitless, $1.0 \mathrm{~min}$; split flow, 30-40 ml/min; purge flow, 1-2 ml/ min; and temperature equilibration time, $2 \mathrm{~min}$. The mass spectrometer was tuned and calibrated prior to all analyses. It was tuned to a minimum resolution of $10,000 \mathrm{ppm}$ ( $10 \%$ valley) using $\mathrm{m} / \mathrm{z}=330.9792$ (or any suitable reference peak) at full accelerating voltage of 8,000 V. Pertinent MS parameters were as follows: cycle time for each congener group, $\sim 1.0$ s; ESA sweep (analytes), 10 ppm; native ion dwell, 100 ms; ${ }^{13} \mathrm{C}$-labeled ion dwell, 35 ms; lock mass sweep, 200 ppm; lock mass dwell, 50 ms; ionization voltage, 35 eV; source temperature, $250^{\circ} \mathrm{C}$; accelerating voltage, 8,000 V; and trap current, $500 \mu \mathrm{A}$.

Quality Control and Calibration. Between four and six calibration standards with native analyte concentrations bracketing the expected analyte concentrations were analyzed prior to analyzing samples. The analyses of calibration standards permitted the response 
factors to be determined as a function of concentration using linear regression. The response factor $(\mathrm{RF})$ for each native analyte at each concentration was calculated relative to its ${ }^{13} \mathrm{C}$-labeled analog. The relative standard deviation (RSD) for average response factor for each of the native analytes had to be $<20 \%$. Similarly, the RF for each ${ }^{13} \mathrm{C}$ recovery surrogate relative to the appropriate internal standard was also calculated. The RSD for the average RF for each labeled surrogate had to be $<35 \%$. The calibration curves were considered linear under these conditions, and the analytical system was considered calibrated when these conditions had been satisfied. If these conditions could be not satisfied, corrective actions were taken. The average RFs were used for subsequent quantitations. Prior to sample analysis, the linearity of the calibration curve was verified by analyzing calibration solution 2 (200 fg of TCDD) and calculating the RF as described previously. The percent difference between the new RF and the average had to be $<20 \%$ for the native analytes and $<35 \%$ for the ${ }^{13} \mathrm{C}$ recovery surrogates. The mass chromatogram was also examined to ensure that all the 2,3,7,8-Cl-substituted congeners were clearly separated. If the $S / N$ values were $\geq 10$, the ion abundance ratios were $\pm 15 \%$ of the theoretical, and the RF and isomer separations were within specified limits, then sample analyses proceeded. Corrective actions were initiated if specified control limits were exceeded. On the days that samples were analyzed, $10 \mu \mathrm{l}$ of the internal standard solution (20 pg/ $\mu \mathrm{l})$ was added to each sample, and the final volume was adjusted to $20 \mu \mathrm{l}$. Once all QA/QC parameters had been verified to be within specified limits, sample analyses proceeded. The mass spectrometer was operated in a mass drift correction mode using PFK to provide lock masses. The selected ion current profile (SICP) areas for the characteristic ions for each native and labeled analyte were measured. Native analyte concentrations were determined by isotope dilution. Peak areas from the characteristic 
ions for each native analyte and its ${ }^{13} \mathrm{C}$-labeled analog were used in conjunction with RFs from the internal calibration data to determine concentrations directly. Labeled surrogate concentrations (expressed as \% recovery) were similarly calculated using an internal standard method. Samples were organized and analyzed in sets: method blank, matrix blank, laboratory control spike (LCS), and the nine samples. Peak identification criteria were as follows: $\mathrm{S} / \mathrm{N} \geq 3.5$; the isotope ratio of the two characteristic ions for each congener class within $15 \%$ of the theoretical value; the peak maxima for the molecular cluster ions coincide within $2 \mathrm{~s}$; and native analytes elute within \pm 3 s of their corresponding ${ }^{13} \mathrm{C}$-labeled analogs. Method blanks were examined for the presence of interfering background. For furans, an ion for the appropriate chlorinated diphenyl ether was monitored and the ion chromatogram examined to ensure the absence of chlorinated diphenyl ether contamination. The amount of any native analyte detected was listed on the quantitation report, along with the recovery of its labeled analog. Recoveries of ${ }^{13} \mathrm{C}$ labeled analogs for the samples were between 30 and 150\%. Sample sets were reviewed by the QA/QC officer to ensure compliance with QA/QC guidelines/criteria. The analytical detection limits ranged from $0.5 \mathrm{pg}$ for TCDD/F to $20 \mathrm{pg}$ for OCDD/F, and from 1 pg (PCB-169) to 500 pg (PCB-118) for the individual PCBs. 
Table S1. National Dioxin Air Monitoring Network Sites

\begin{tabular}{|c|c|c|c|c|c|}
\hline $\begin{array}{l}\text { Site } \\
\text { No. }\end{array}$ & Name & $\begin{array}{c}\text { Latitude } \\
\text { D/M/S }\end{array}$ & $\begin{array}{l}\text { Longitude } \\
\text { D/M/S }\end{array}$ & $\begin{array}{c}\text { Elevation } \\
\text { meters }\end{array}$ & Classification \\
\hline 1 & Penn Nursery, PA & 404630 & 773717 & 466 & Rural \\
\hline 2 & Penn Nursery, PA (duplicate) & 404630 & 773717 & 466 & Rural \\
\hline 3 & Clinton Crops, NC & 350133 & 781639 & 40 & Rural \\
\hline 4 & Everglades, FL & 252324 & 804048 & 2 & Rural \\
\hline 5 & Lake Dubay, WI & 443952 & 893908 & 350 & Rural \\
\hline 6 & Monmouth, IL & 405602 & 904323 & 230 & Rural \\
\hline 7 & McNay, IA & 405747 & 932330 & 320 & Rural \\
\hline 8 & Lake Scott, KS & 384019 & 1005505 & 863 & Rural \\
\hline 9 & Bixby/Lake Keystone, OK & 360819 & 961548 & 260 & Rural \\
\hline 10 & Arkadelphia, AR & 341046 & 930555 & 71 & Rural \\
\hline 11 & Bennington, VT & 425234 & 730948 & 305 & Rural \\
\hline 12 & Jasper, NY & 420623 & 773209 & 634 & Rural \\
\hline 13 & Beltsville, MD & 390100 & 765645 & 46 & Urban \\
\hline 14 & Caldwell, $\mathrm{OH}$ & 394734 & 813152 & 276 & Rural \\
\hline 15 & Oxford, OH & 393153 & 844327 & 284 & Rural \\
\hline
\end{tabular}




\begin{tabular}{|c|c|c|c|c|c|}
\hline 16 & Dixon Springs, IL & 3737608 & 2884019 & 161 & Rural \\
\hline 17 & Quincy, FL & 303253 & 843603 & 60 & Rural \\
\hline 18 & Bay St. Louis, MS & 302206 & 893701 & 8 & Rural \\
\hline 19 & Padre Island, TX & 272537 & 971755 & 8 & Rural \\
\hline 20 & Fond du Lac, MN & 464247 & 923039 & 390 & Rural \\
\hline 21 & North Platte, NE & 410333 & 1004447 & 919 & Rural \\
\hline 22 & Goodwell, OK & 363527 & 1013703 & 999 & Rural \\
\hline 23 & Big Bend, TX & 291808 & 1031038 & 1056 & Remote \\
\hline 24 & Grand Canyon, AZ & 360335 & 1121101 & 2152 & Remote \\
\hline 25 & T. Roosevelt N.P., ND & 465341 & 1032240 & 841 & Remote \\
\hline 26 & Craters Moon, ID & 432741 & 1133317 & 1807 & Remote \\
\hline 27 & Chiricahua, AZ & 320035 & 1092320 & 1570 & Remote \\
\hline 28 & Rancho Seco, CA & 382036 & 1210627 & 64 & $\begin{array}{l}\text { Rural } \\
\text { na }\end{array}$ \\
\hline 29 & Hyslop Farm, OR & 443805 & 1231124 & 69 & Rural \\
\hline 30 & Ozette Lake, WA & 480913 & 1244004 & 25 & Remote \\
\hline 31 & Fort Cronkhite, CA & 375003 & 1223154 & 30 & Urban \\
\hline 32 & Newport, OR & 443718 & 1240235 & 5 & Urban \\
\hline 33 & Craig, AK & 552819 & 1330749 & 5 & Rural \\
\hline 34 & Trapper Creek, AK & 621857 & 1501842 & 150 & Remote \\
\hline
\end{tabular}


- 8 - 
Table S2. Summary of mean annual average air concentration (fg $\mathrm{m}^{-3}$ ) of PCDD, PCDF and coplanar PCB congeners (along with their TEQs) in rural and remote NDAMN sites in 1999, 2000, 2001, and 2002

\begin{tabular}{|c|c|c|c|c|c|c|c|c|}
\hline & \multicolumn{2}{|c|}{1999} & \multicolumn{2}{|c|}{2000} & \multicolumn{2}{|c|}{2001} & \multicolumn{2}{|c|}{2002} \\
\hline & RURAL & REMOTE & RURAL & REMOTE & RURAL & REMOTE & RURAL & REMOTE \\
\hline 2,3,7,8-TCDD & 0.53 & 0.03 & 0.54 & 0.03 & 0.52 & 0.02 & 0.55 & 0.07 \\
\hline 1,2,3,7,8-PeCDD & 3.01 & 0.37 & 3.15 & 0.24 & 3.10 & 0.14 & 3.47 & 0.36 \\
\hline 1,2,3,4,7,8-HxCDD & 4.07 & 0.71 & 4.25 & 0.37 & 4.04 & 0.26 & 4.59 & 0.40 \\
\hline 1,2,3,6,7,8-HxCDD & 7.72 & 1.28 & 8.50 & 0.88 & 7.53 & 0.51 & 8.20 & 0.74 \\
\hline 1,2,3,7,8,9-HxCDD & 7.22 & 1.08 & 8.48 & 0.79 & 7.21 & 0.48 & 8.19 & 0.66 \\
\hline $1,2,3,4,6,7,8-H p C D D$ & 105.50 & 16.05 & 117.23 & 11.96 & 106.14 & 8.97 & 122.11 & 10.07 \\
\hline$O C D D$ & 345.16 & 43.95 & 433.93 & 46.28 & 361.86 & 31.12 & 408.94 & 34.51 \\
\hline 2,3,7,8-TCDF & 1.95 & 0.16 & 2.25 & 0.21 & 1.88 & 0.25 & 1.69 & 0.23 \\
\hline 1,2,3,7,8-PeCDF & 2.06 & 0.30 & 2.33 & 0.11 & 1.99 & 0.16 & 1.65 & 0.24 \\
\hline 2,3,4,7,8-PeCDF & 3.73 & 0.50 & 4.08 & 0.35 & 3.42 & 0.27 & 2.92 & 0.33 \\
\hline 1,2,3,4,7,8-HxCDF & 4.30 & 0.58 & 4.98 & 0.47 & 4.70 & 0.39 & 3.65 & 0.50 \\
\hline 1,2,3,6,7,8-HxCDF & 3.90 & 0.51 & 4.56 & 0.45 & 4.22 & 0.37 & 3.44 & 0.42 \\
\hline 2,3,4,6,7,8-HxCDF & 5.23 & 0.78 & 6.30 & 0.67 & 5.64 & 0.61 & 4.76 & 0.64 \\
\hline 1,2,3,7,8,9-HxCDF & 1.61 & 0.29 & 0.91 & 0.07 & 0.51 & 0.03 & 0.41 & 0.06 \\
\hline 1,2,3,4,6,7,8-HpCDF & 21.57 & 3.26 & 27.42 & 3.04 & 27.05 & 2.99 & 20.27 & 3.78 \\
\hline 1,2,3,4,7,8,9-HрCDF & 2.81 & 0.53 & 3.45 & 0.31 & 3.15 & 0.21 & 2.27 & 0.49 \\
\hline$O C D F$ & 18.90 & 7.57 & 29.67 & 4.84 & 18.39 & 2.75 & 14.72 & 6.00 \\
\hline Total TCDD & 12.50 & 0.70 & 16.49 & 1.47 & 14.14 & 0.73 & 18.35 & 1.33 \\
\hline
\end{tabular}




\begin{tabular}{|c|c|c|c|c|c|c|c|c|}
\hline & RURAL & REMOTE & RURAL & REMOTE & RURAL & REMOTE & RURAL & REMOTE \\
\hline Total PeCDD & 25.88 & 1.72 & 32.16 & 2.23 & 34.76 & 1.60 & 45.30 & 3.45 \\
\hline Total $H x C D D$ & 102.34 & 13.33 & 106.54 & 11.85 & 104.37 & 8.11 & 123.62 & 9.88 \\
\hline Total HpCDD & 242.58 & 34.94 & 263.47 & 27.06 & 250.76 & 16.69 & 294.55 & 22.04 \\
\hline Total TCDF & 76.37 & 7.64 & 76.37 & 11.18 & 71.09 & 7.68 & 62.99 & 8.16 \\
\hline Total PeCDF & 47.38 & 2.63 & 48.75 & 4.82 & 43.01 & 2.43 & 41.38 & 5.28 \\
\hline Total $H x C D F$ & 50.32 & 4.88 & 52.56 & 5.97 & 53.10 & 5.69 & 46.24 & 6.34 \\
\hline Total HpCDF & 36.92 & 5.26 & 45.49 & 4.89 & 41.98 & 3.81 & 34.47 & 6.07 \\
\hline$P C D D+P C D F$ & 958.35 & 122.62 & $1,105.43$ & 120.59 & 993.45 & 80.61 & $1,090.56$ & 103.05 \\
\hline$T E Q_{D F}$ & 10.43 & 1.41 & 11.39 & 0.99 & 10.40 & 0.70 & 10.47 & 1.07 \\
\hline PCB-77 & 45.37 & 14.58 & 140.84 & 58.05 & 54.47 & 7.85 & 48.13 & 31.87 \\
\hline РСB-105 & 289.04 & 167.36 & 684.62 & 334.28 & 333.80 & 24.97 & 280.64 & 129.87 \\
\hline РСВ-118 & 810.16 & 520.30 & $1,671.08$ & 871.65 & 832.10 & 462.05 & $1,104.79$ & 360.62 \\
\hline РСВ-126 & 4.68 & 1.17 & 6.73 & 1.43 & 4.43 & 1.25 & 4.58 & 1.42 \\
\hline РСВ-156 & 52.83 & 37.21 & 102.99 & 61.45 & 54.91 & 41.64 & 45.42 & 16.49 \\
\hline РСB-157 & 11.60 & 10.43 & 20.86 & 12.71 & 12.16 & 9.39 & 9.72 & 3.27 \\
\hline РСВ-169 & 0.60 & 0.06 & 0.84 & 0.06 & 0.64 & 0.01 & 0.68 & 0.03 \\
\hline$T E Q_{P C B}$ & 0.62 & 0.16 & 0.69 & 0.22 & 0.59 & 0.18 & 0.70 & 0.32 \\
\hline
\end{tabular}




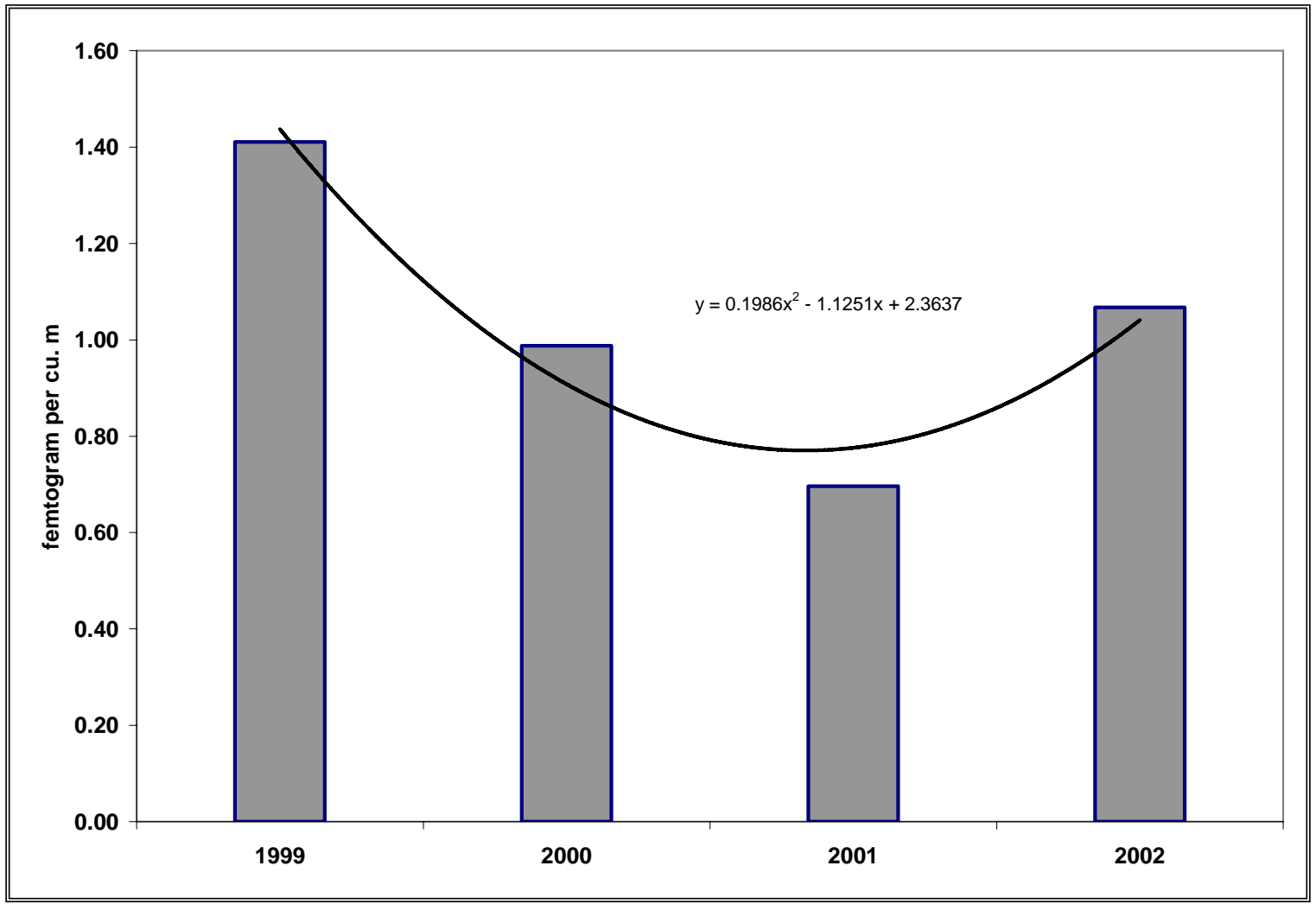

Figure S1. Mean annual ambient air concentration $\left(\mathrm{fg}^{-3}\right)$ of WHO-TEQDF at remote NDAMN sites. 


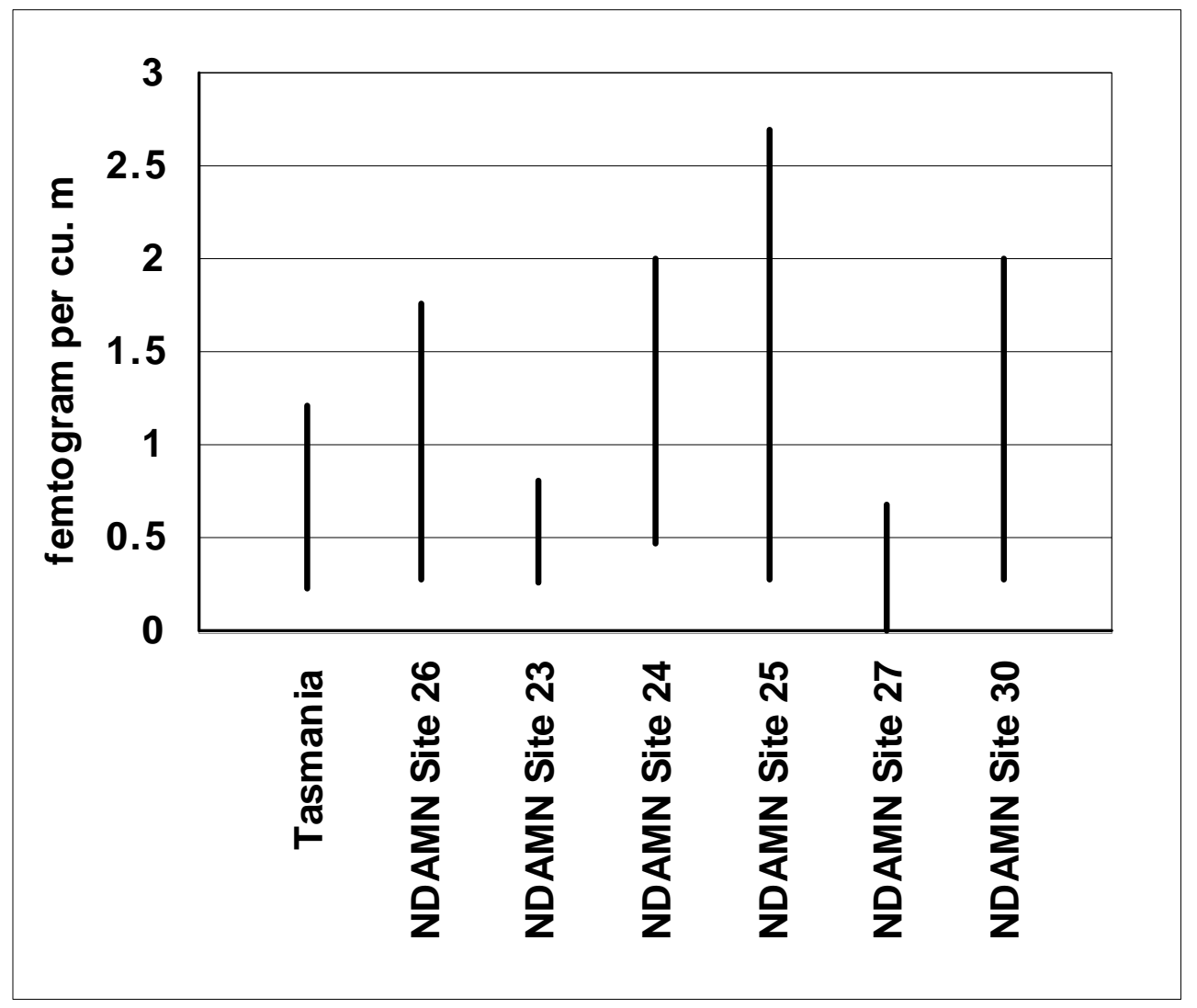

Figure S2. Comparison of ranges in TEQ remote areas to Tasmania in the year 2002. 
Q Rural $\square$ Remote

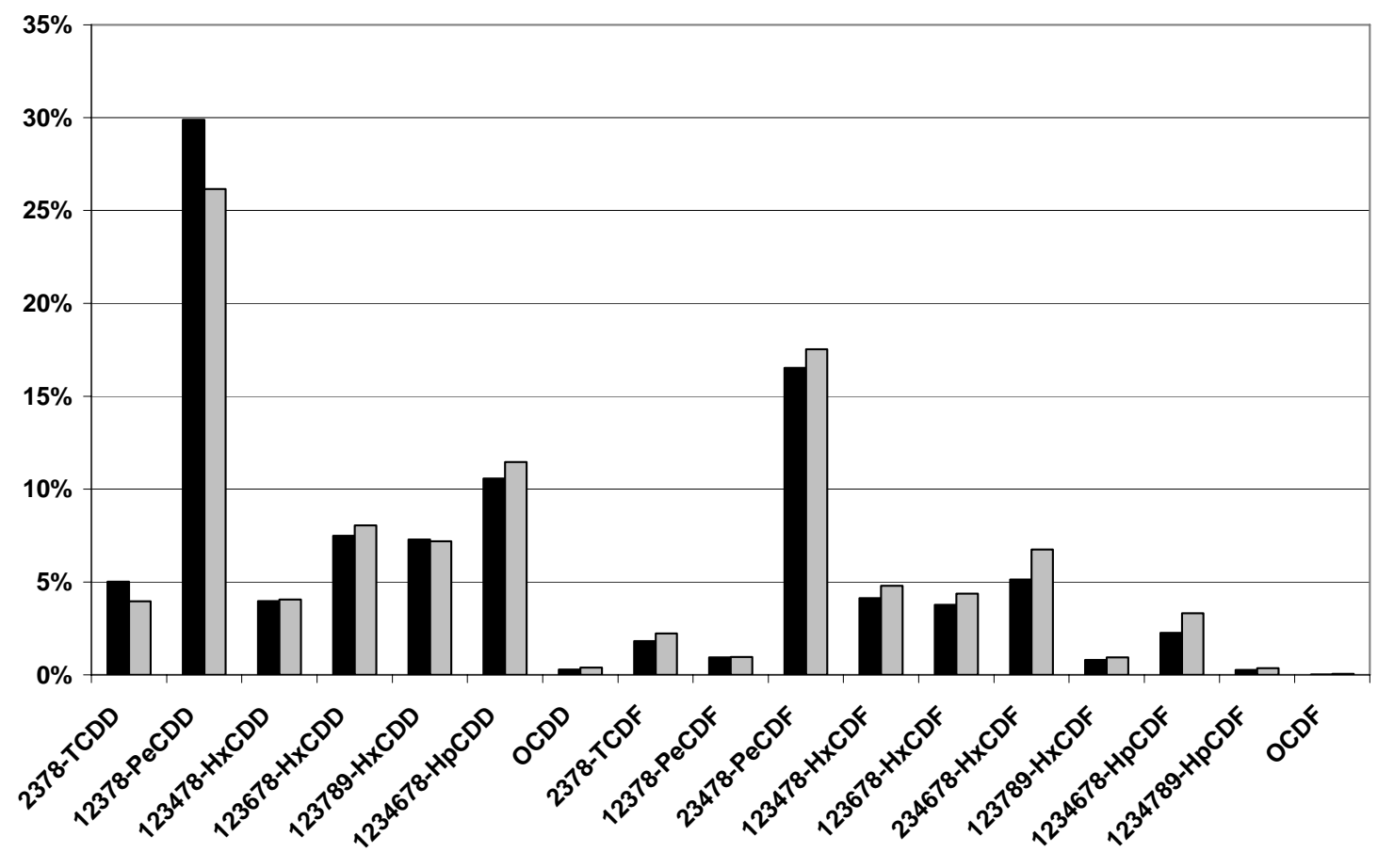

Figure S3. Mean PCDD and PCDF congener profile in rural and remote NDAMN sites (percent of TEQ) 
Figure S4. PCDD/PCDF congener pattern in air of an urban center from two sampling periods one year apart (2000 and 2001).
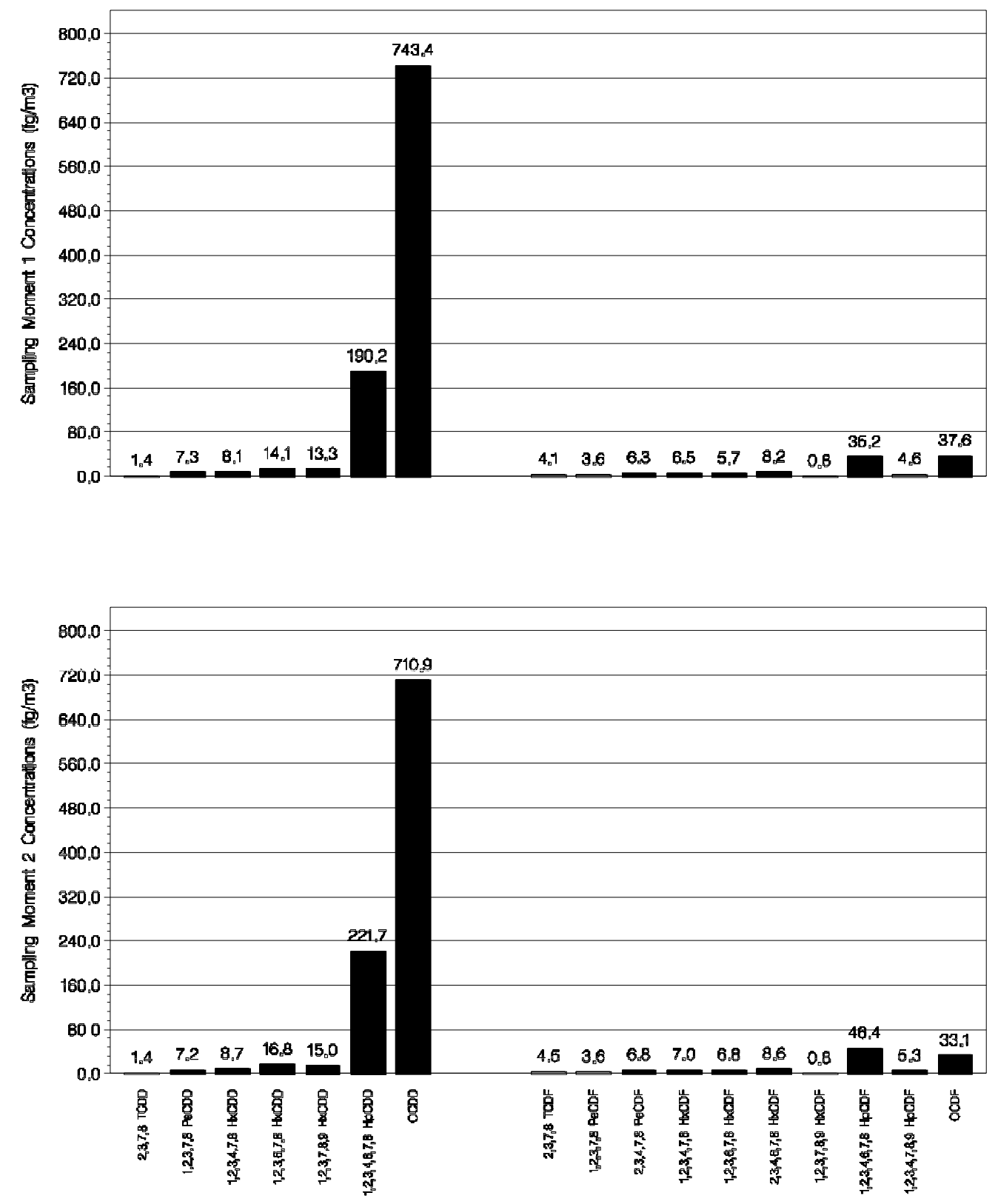


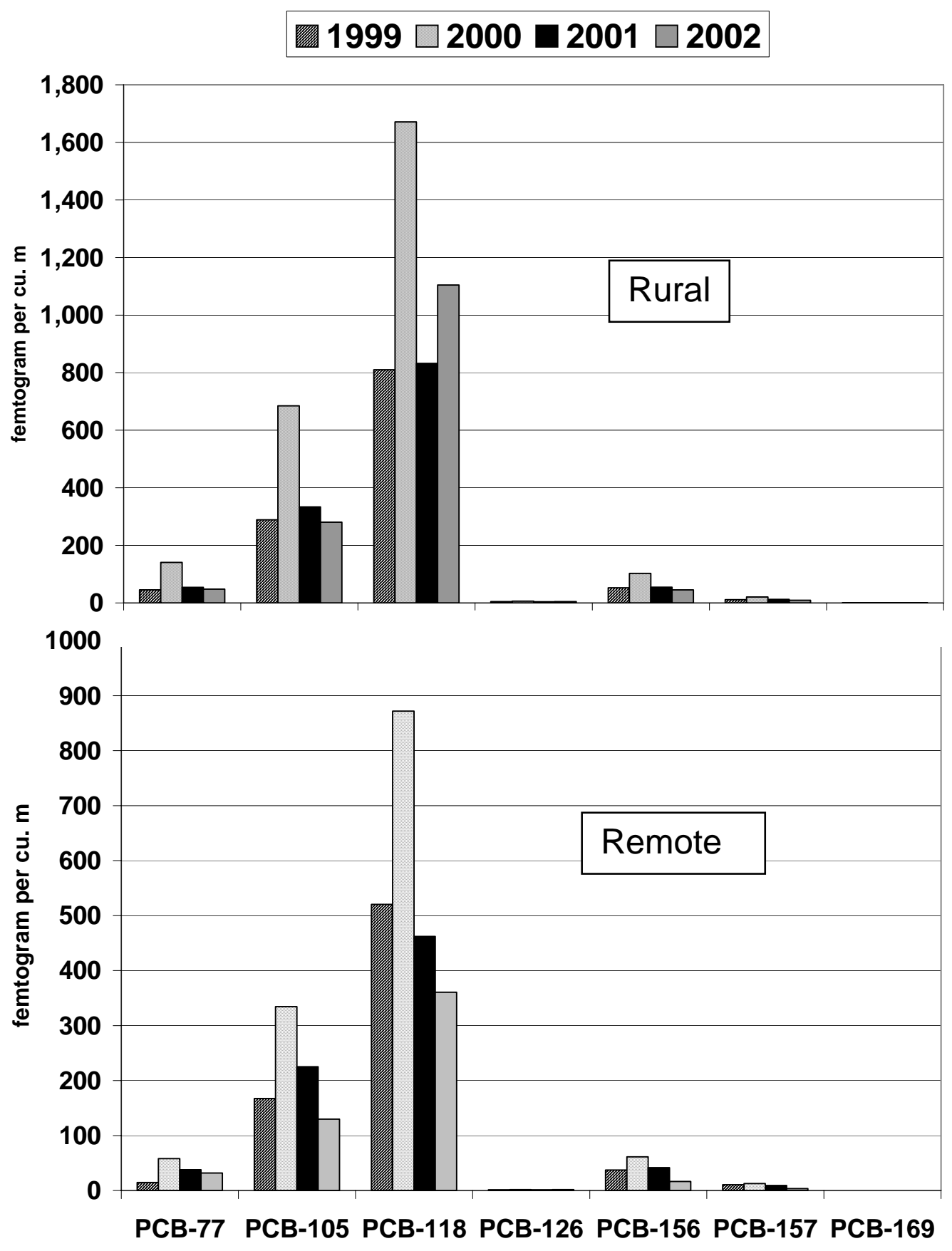

Figure S5. The mean coplanar PCB congener profile at rural and remote NDAMN sites from1999-2002 